\title{
Epilepsy in Older People in Sub-Saharan Africa: A Systematic Review
}

\author{
Felix Bongomin (D) \\ Elly Katabira \\ Martha Sajatovic \\ Mark Kaddumukasa $(\mathbb{D}$ \\ 'Department of Medicine, School of \\ Medicine, College of Health Sciences, \\ Makerere University, Kampala, Uganda; \\ ${ }^{2}$ Department of Medical Microbiology \& \\ Immunology, Faculty of Medicine, Gulu \\ University, Gulu, Uganda; ${ }^{3}$ Neurological \\ and Behavioral Outcomes Center, \\ University Hospitals Cleveland Medical \\ Center \& Case Western Reserve \\ University School of Medicine, Cleveland, \\ $\mathrm{OH}, 44106$, USA
}

Background: Over one-fourth of new onset epilepsy occurs after age 60. However, the burden of epilepsy and other seizure disorders among this special population in Africa is largely unknown, despite a growingnumber of elderly persons on the continent. This study aimed to assess the prevalence and risk factors for epilepsy among persons aged 60 years or older in Africa.

Methods: We conducted a systematic review by searching MEDLINE (via) and EMBASE databases from inception to 30th October 2020. Primary researches reporting prevalence or incidence of seizures or epilepsy in older persons ( $\geq 60$ years) were included. Review articles were excluded.

Results: We retrieved 107 citations from which 4 studies, recruiting 10, 334 participants were eligible. The studies were conducted between 1999 and 2018 and published between 2005 and 2019. Two of the studies were conducted in the West African countries of Niger and Senegal; meanwhile, the remaining 2 were conducted in East African country of Tanzania. Regarding study design, three were either hospital-based or community-based cross-sectional studies. Meanwhile, 1 was a retrospective hospital-based study. Of the 10,334 participants, $81(0.78 \%)$ had a seizure disorder. The prevalence of seizure ranged from $0.02 \%$ to $3.2 \%$.

Conclusion: There are limited data on the prevalence of epilepsy in older persons in older adults in most countries in sub-Saharan Africa. Epilepsy among the older adults remains a challenge in Africa and more information is needed to understand the burden to improve care.

Keywords: seizure, epilepsy, elderly persons, sub-Saharan Africa

\section{Plain Language Summary}

Epilepsy is a chronic neurological disorder that affects people of all ages and gender. There is an increasing interest in the epidemiology of new-onset and prevalent epilepsy among older people globally. Epilepsy among older people can be due to a myriad of underlying factors that may cause structural brain changes. These underlying diseases include stroke, dementia, brain tumors, chronic heart diseases and chronic infectious etiologies such as neurocysticercosis, syphilis and HIV in endemic areas such as sub-Saharan Africa (SSA). However, little is known about the burden of epilepsy, especially among older persons in this region. In this study, we sought to determine the prevalence of epilepsy among older people in SSA. We found very limited literature regarding this subject in the literature. In the four eligible studies included in the qualitative synthesis, the prevalence of seizure and epilepsy among persons aged 60 years or older in from $0.02 \%$ to $3.2 \%$. With the older population rising three times more quickly in resource poor settings compared to more advanced economies and epilepsy being more prevalent in older people, the burden of
Correspondence: Felix Bongomin Department of Medical Microbiology \& Immunology, Faculty of Medicine, Gulu University, P.O. Box 166, Gulu, Uganda Email drbongomin@gmail.com 
epilepsy in SSA will potentially increase substantially in the near future. We recommend that more information is needed to understand the burden of epilepsy among older people in SSA to improve care.

\section{Background}

Epilepsy, a chronic, non-communicable neurological disease characterized by recurrent seizures is estimated to affect approximately 50 million people of all ages, making it one of the most common neurological diseases globally. ${ }^{1,2}$ Over $80 \%$ of the global burden of epilepsy is in low- and middle-income countries (LMICs), where secondary causes of epilepsy such as neurocysticercosis and traumatic brain injuries are highly prevalent. ${ }^{1,3}$

Epilepsy has for long been misunderstood as a disease of the young, however, both the incidence and prevalence of epilepsy increase throughout adulthood. ${ }^{4,5}$ In fact, the incidence of seizures and epilepsy in the elderly population is increasingly being recognized and constitutes a significant proportion of the global burden of the disease. $^{6-8}$

In the elderly, seizures and new-onset epilepsy can be attributed in large part to the high prevalence of underlying etiology, including cerebrovascular diseases, primary neurodegenerative disorders, intracerebral tumors, and traumatic brain injury. ${ }^{8-10}$ Metabolic derangements and intoxications in older people are some of the most common causes of acute symptomatic seizures. ${ }^{10}$

In Africa, the number of people aged 60 years and above are projected to rise to over 67 million by $2030 .{ }^{11}$ Therefore, it is very predictable the burden of age-related diseases such as dementias will increase several folds. Moreover, the prevalence of seizures and new-onset epilepsy is more and tends to have earlier onset in patients with cognitive decline when compared with age-matched cognitively normal population. ${ }^{12-14}$ This burden is in addition to the growing number of persons living with epilepsy (PWE) who are now growing with the disease up to old age ( $>60$ years), given the improved medical care and improved survival among PWE. ${ }^{8}$

Despite the growing numbers of older persons in Africa, the burden of seizures and epilepsy among the elder population and more so in those with cognitive decline in Africa is not known, mainly because there has been limited research among this population. In a previous (2014) meta-analysis, the prevalence of epilepsy in subSaharan Africa was estimated at $9.4 \% .{ }^{15}$ In this study, the prevalence of epilepsy in older persons was not reported.
Therefore, the true burden of epileptic seizures occurring in older persons in Africa remains unknown. Moreover, the epidemiology of epilepsy varies across countries. This study aimed at systematically reviewing the available published literature on the prevalence of epilepsy in the elderly population in Africa.

\section{Methods \\ Study Design}

This systematic review was conducted in accordance with the Preferred Reporting Items for Systematic Reviews and Meta-Analyses (PRISMA) guided by the PRISMA checklist. $^{16}$

\section{Search Strategy}

We performed a systematic review in accordance to the Preferred Reporting Items for Systematic Review and Meta-Analysis (PRISMA) checklists. We searched the electronic medical databases MEDLINE (through PubMed) and EMBASE from inception to 30th October 2020, using the following Medical Subheading (MeSH) terms: "new-onset", "newly diagnosed", "epilepsy”, “epilep*”, “seizures" “causes", “EEG”, “prevalence", "incidence", AND "elderly" AND "Africa" or each of the 54 countries in Africa. The language of article search was restricted to English. Additional articles were retrieved through manual search of references on all citations that met the inclusion criteria for our study and grey literature (Figure 1).

\section{Selection Criteria}

People aged $\geq 60$ years with a diagnosis of epilepsy or seizures were included. We excluded studies where age was not indicated. All study types (both qualitative and quantitative) were included, except for reviews. We included all studies that reported the prevalence, incidence, etiology, prognosis (outcomes), treatment and psychosocial impact of seizure or epilepsy. We excluded case reports and case series with 10 participants or less.

\section{Data Curation and Analysis}

All titles and abstracts of studies were independently screened using the predetermined eligibility criteria by authors K.M. and F.B.

Data were extracted from the studies according to the study design, number of participants, type of epilepsy, main findings and type of treatment studied. Following 


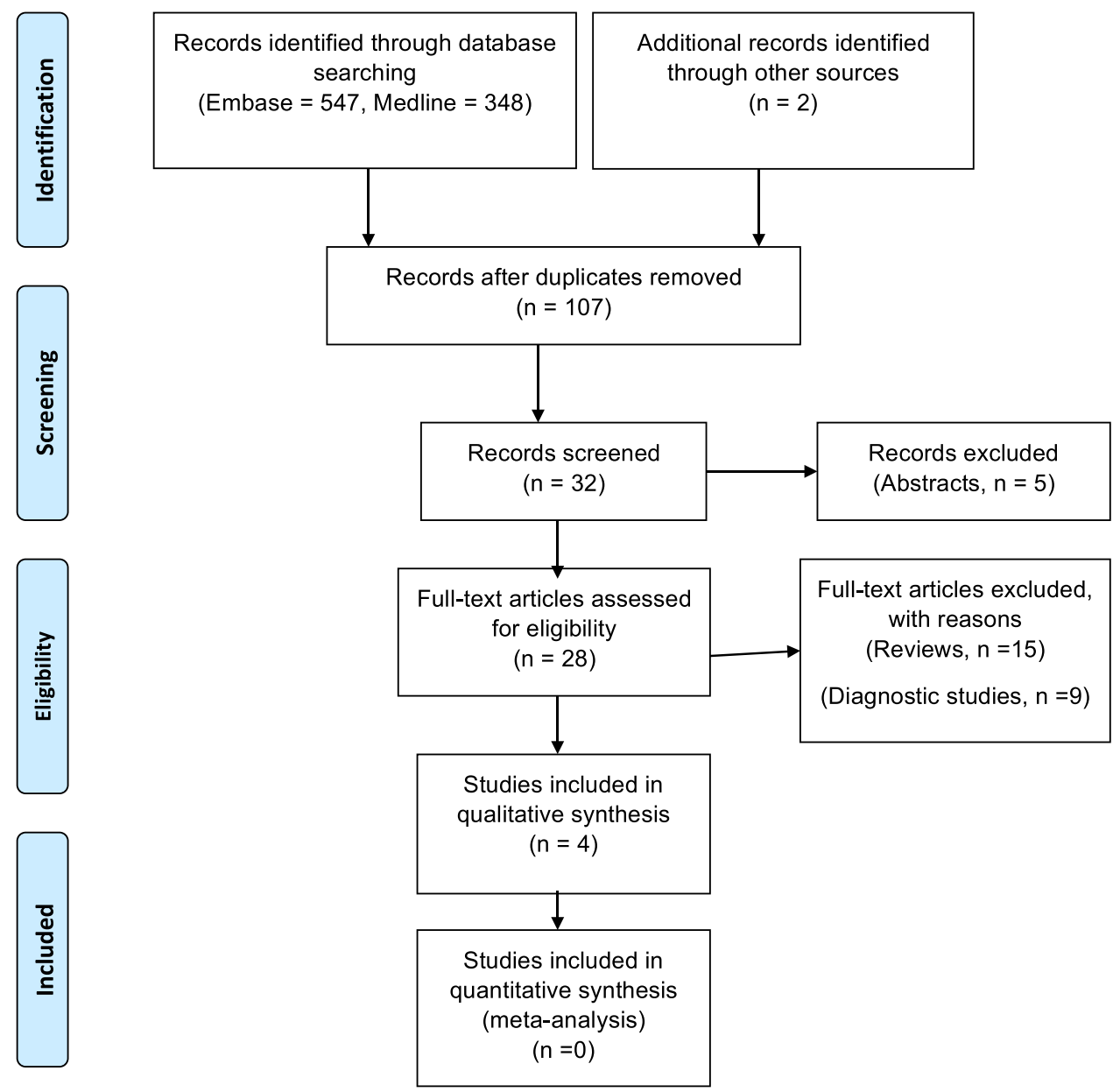

Figure I PRISMA flow diagram.

Notes: PRISMA figure adapted from Liberati A, Altman D, Tetzlaff J, et al. The PRISMA statement for reporting systematic reviews and meta-analyses of studies that evaluate health care interventions: explanation and elaboration. Journal of Clinical Epidemiology. 2009;62(10)el-e34. ${ }^{24}$ Creative Commons.

extraction, the data were analyzed and summarized qualitatively. A formal meta-analysis was not conducted given the small number of reports and variability in sample selection and study design.

\section{Study Quality}

All the eligible studies included were assessed for risk of bias using the Newcastle Ottawa Scale. The risk of bias in individual studies was graded as low, moderate, and high.

\section{Results}

\section{Study Characteristics}

We included 4 eligible studies, ${ }^{17-20}$ recruiting 10,334 participants. Regarding study design, three were either hospital-based ${ }^{19,20}$ or community-based ${ }^{18}$ cross-sectional studies. One was a retrospective hospital-based study ${ }^{17}$ (Table 1). The studies were conducted between 1999 and
2018 and published between 2005 and 2019. Two of the studies were conducted in the West African countries of Niger ${ }^{17}$ and Senegal; ${ }^{19}$ meanwhile, the remaining $2^{18,20}$ were conducted in East African country of Tanzania.

\section{Prevalence of Seizure}

Of the 10, 334 participants studied, $81(0.78 \%)$ participants aged 60 years or older had epilepsy. The prevalence of seizure ranged from $0.02 \%$ to $3.2 \%$ (Table 1 ).

Only one study ${ }^{17}$ reported the possible etiologies of the seizures among the elderly population, with nearly twothirds not determined, while post-stroke epilepsy was the commonest especially within the 60-64 age group. This was followed by cerebral toxoplasmosis, brain tumors at 2 (3.2\%), respectively, and one had cerebral meningioma. The other studies did not report on the possible risk factors within this elderly age group. 
Table I Study Characteristics

\begin{tabular}{|c|c|c|c|c|c|c|c|c|}
\hline $\begin{array}{l}\text { Author } \\
\text { (Reference) }\end{array}$ & Country & Study Design & Age & Sex & Study Period & $\begin{array}{l}\text { Sample Size } \\
\text { (Epilepsy/ } \\
\text { Population } \\
\text { Studied) }\end{array}$ & Prevalence & Others \\
\hline $\begin{array}{l}\text { Assadeck } \\
\text { et al } 2019^{17}\end{array}$ & Niger & $\begin{array}{l}\text { Retrospective, } \\
\text { hospital based }\end{array}$ & $\begin{array}{l}\text { Mean age, } \\
65.8 \pm 5.7 \\
\text { (range: } 60 \\
\text { and } 83 \text { ) years }\end{array}$ & $\begin{array}{l}\text { Male } 38 \\
(61.3 \%)\end{array}$ & $\begin{array}{l}\text { May } 2013 \text { to } \\
\text { May } 2018\end{array}$ & $62 / 4576$ & $1.35 \%$ & $\begin{array}{l}\text { The } 4757 \\
\text { patients were } \\
\text { of all ages }\end{array}$ \\
\hline $\begin{array}{l}\text { Toure et al } \\
2012^{19}\end{array}$ & Senegal & $\begin{array}{l}\text { Cross- } \\
\text { sectional, } \\
\text { hospital-based }\end{array}$ & $65+$ years & $\begin{array}{l}\text { Not } \\
\text { indicated }\end{array}$ & $\begin{array}{l}\text { March } 2004 \text { to } \\
\text { December } 2005\end{array}$ & $7 / 507$ & $1.4 \%$ & - \\
\hline $\begin{array}{l}\text { Winkler et al } \\
2008^{20}\end{array}$ & Tanzania & $\begin{array}{l}\text { Cross- } \\
\text { sectional, } \\
\text { hospital-based }\end{array}$ & $60+$ years & $4 \mathrm{~F} / 7 \mathrm{M}$ & $\begin{array}{l}\text { August } 2002 \text { to } \\
\text { September } 2004\end{array}$ & $11 / 346$ & $3.2 \%$ & $\begin{array}{l}\text { All } 346 \\
\text { patients had } \\
\text { epilepsy }\end{array}$ \\
\hline $\begin{array}{l}\text { Dent et al } \\
2005^{18}\end{array}$ & Tanzania & $\begin{array}{l}\text { Cross- } \\
\text { sectional, } \\
\text { community- } \\
\text { based }\end{array}$ & $60-69$ years & Male & $\begin{array}{l}\text { August and } \\
\text { December of } \\
1999\end{array}$ & $1 / 4905$ & $0.02 \%$ & $\begin{array}{l}\text { Door-to-door } \\
\text { survey in the } \\
\text { selected } \\
\text { households }\end{array}$ \\
\hline
\end{tabular}

\section{Discussions}

Despite global data suggesting an increased incidence and prevalence of seizures and epilepsy in the elderly population over the past few decades, ${ }^{6-8}$ the burden of seizure disorders among the elderly population in sub-Saharan Africa is largely unknown. In this systematic review, we report a prevalence of seizure disorders among people aged 60 years or older in sub-Saharan Africa to ranging from $0.02 \%$ to $3.2 \%$. With the rapidly growing number of people aged 60 years and above being projected to rise to over 67 million by 2030 in sub-Saharan Africa, this prevalence will translate into a considerable burden of seizure disorders in the region. ${ }^{11}$ Moreover, the age threshold for older persons can start from as early as the age of 50 years. ${ }^{8}$ A community-based study recruiting patients aged 50 years or older in Nigeria reported a lifetime seizure prevalence of $0.6 \%$ and that of epilepsy at $0.009 \%{ }^{21}$

Epilepsy is the third most common neurological disorder in older people persons after cerebrovascular accident (CVA) and dementias, conditions which themselves increase seizure risk. $^{2}$ In developing countries, CVA is the most important cause of new onset seizures in the elderly. However, many other factors including metabolic derangements such as hyponatremia, intracerebral tumors, excessive use of alcohol and recreational drugs, meningitis, and traumatic brain injury are important risk factors for new-onset seizures in this population..$^{8-10}$ Only one of the 4 studies included in the present study investigated the etiology of seizure among the study participants, ${ }^{17}$ with post stroke being the commonest cause. Two-thirds of the study population had no determined cause. This might be attributed to the fact that in older adults, the development of epilepsy is likely to be secondary to the presence of another comorbid condition (symptomatic epilepsy). ${ }^{22,23}$ Implications of comorbid conditions such as stroke or tumors may further complicated treatment and care, increase in adverse effects and impact on activities of daily living. The presentation of epilepsy in old age may be less specific with majority and requires a high index of suspicion.

\section{Limitations}

Our literature search focused on studies published in 1999-2018. As with any search, we may not have identified all pertinent articles, and our search and review strategy may have introduced some bias. The fact that we only included English-language articles could have missed articles written in other languages. Another limitation is that we could not compare the frequency and etiology of epilepsy across SSA due to the differences in study designs and methods. Also, the definition of seizure has evolved in the past few years, and these may not have been reflected in the included studies. Therefore, the reported prevalence may be an underestimation of the true burden of epilepsy in this population. Finally, there were only a limited 
number of publications and hence a very narrow study population, which may limit the approximation of the prevalence and burden of epilepsy in the elderly.

\section{Conclusion}

There are limited data on the prevalence of epilepsy in older persons in sub-Saharan Africa. Factors linked with ageing in addition to a diagnosis of epilepsy can result in older adults with epilepsy being a vulnerable population group. It is important to understand the prevalence of epilepsy in the older people to prioritize early diagnosis and clinical care. Even though the population of older adults is increasing with epilepsy, there is still limited literature on the burden of their disease. Finally, the information currently available on the subject needs to be further explored by well-designed studies with a greater number of participants, EEG monitoring and neuroimaging studies, so as to enable the adoption of better practices regarding treatment and prognosis.

\section{Funding}

The study was supported by a grant from the National Institutes Health (3K43TW010401-04S1 National Institute of Health (NIH) and Fogarty International Center (FIC) to Mark Kaddumukasa). The contents of this manuscript are solely the responsibility of the authors and do not necessarily represent the official views of the NIH.

\section{Disclosure}

Professor Martha Sajatovic reports grants from Nuromate, Otsuka, Alkermes, International Society for Bipolar Disorders (ISBD) and personal fees from Alkermes, Otsuka, Janssen, Myriad, Health Analytics, Frontline Medical Communications, Springer Press, Johns Hopkins University Press, Oxford Press, UpToDate, American Physician's Institute, MCM Education, CMEology, Potomac Center for Medical Education, Global Medical Education, Creative Educational Concepts, and Psychopharmacology Institute, outside the submitted work. The authors declare that they have no other potential conflicts of interest for this work.

\section{References}

1. World Health Organization. Epilepsy. World Health Organization; 2019. Available from: https://www.who.int/en/news-room/fact-sheets /detail/epilepsy. Accessed October 30, 2020.

2. World Health Organization. Epilepsy: a public health imperative World Health Organization; 2019. Available from: https://www.who. int/publications/i/item/epilepsy-a-public-health-imperative. Accessed May 28, 2021
3. Owolabi LF, Adamu B, Jibo AM, Owolabi SD, Imam AI, Alhaji ID. Neurocysticercosis in people with epilepsy in Sub-Saharan Africa: a systematic review and meta-analysis of the prevalence and strength of association. Seizure. 2020;76:1-11. doi:10.1016/j.seizure.2020. 01.005

4. Hauser WA. Seizure disorders: the changes with age. Epilepsia. 1992;33:6-14. doi:10.1111/j.1528-1157.1992.tb06222.x

5. Paradowski B, Zagrajek MM. Epilepsy in middle-aged and elderly people: a three-year observation. Epileptic Disord. 2005;7:91-95.

6. Tallis R, Hall G, Craig I, Dean A. How common are epileptic seizures in old age? Age Ageing. 1991;20:442-448. doi:10.1093/ageing/20.6.442

7. Ettinger AB, Shinnar S. Seizures in the elderly. Neurology. 1994;44:195. doi:10.1212/WNL.44.1.195

8. Sen A, Jette N, Husain M, Sander JW. Epilepsy in older people. Lancet. 2020;395:735-748. doi:10.1016/S0140-6736(19)33064-8

9. Mendiratta A, Pedley TA. Seizures and epilepsy in the elderly. In: Shorvon S, Pedley T, editors. Blue Books of Neurology. Elsevier; Vol. 33; 2009:177-193. doi:10.1016/B978-1-41606171-7.00013-3

10. Liu S, Yu W, Lü Y. The causes of new-onset epilepsy and seizures in the elderly. Neuropsychiatr Dis Treat. 2016;12:1425-1434. doi:10.2147/NDT.S107905

11. Velkoff VA, Kowal PR. Aging in Sub-Saharan Africa: the changing demography of the region. In: Cohen B, Menken J, editors. National Research Council (US) Committee on Population. 2nd ed. Washington (DC): National Academies Press (US); 2006.

12. Mendez MF, Lim GTH. Seizures in elderly patients with dementia: epidemiology and management. Drugs Aging. 2003;20:791-803. doi:10.2165/00002512-200320110-00001

13. Lyou HJ, Seo K-D, Lee JE, Pak HY, Lee JH. Association of Alzheimer's disease with the risk of developing epilepsy: a 10-year Nationwide Cohort Study. Dement Neurocogn Disord. 2018;17:156. doi:10.12779/dnd.2018.17.4.156

14. Friedman D, Honig LS, Scarmeas N. Seizures and epilepsy in Alzheimer's disease. CNS Neurosci Ther. 2012;18:285-294. doi:10.1111/j.1755-5949.2011.00251.x

15. Ba-Diop A, Marin B, Druet-Cabanac M, Ngoungou EB, Newton CR, Preux PM. Epidemiology, causes, and treatment of epilepsy in sub-Saharan Africa. Lancet Neurol. 2014;13:1029-1044. doi:10.1016/S1474-4422(14)70114-0

16. Moher D, Shamseer L, Clarke M, et al. Preferred reporting items for systematic review and meta-analysis protocols (PRISMA-P) 2015 statement. Syst Rev. 2015;4:1. doi:10.1186/2046-4053-4-1

17. Assadeck H, Toudou-Daouda M, Mamadou Z, Moussa-Konate M, Hassane-Djibo F, Douma-Maiga D. Clinical and etiological characteristics of epilepsy in the elderly: a hospital-based study from a tertiary care referral center of Niamey, Niger. J Neurosci Rural Pract. 2019;10:571-575. doi:10.1055/s-0039-1700308

18. Dent W, Helbok R, Matuja WBP, Scheunemann S, Schmutzhard E. Prevalence of active epilepsy in a rural area in south Tanzania: a door-to-door survey. Epilepsia. 2005;46:1963-1969. doi:10.1111/ j.1528-1167.2005.00338.x

19. Toure K, Coume M, Ndiaye M, et al. Risk factors for Dementia in a senegalese elderly population aged 65 years and over. Dement Geriatr Cogn Dis Extra. 2012;2:160-168. doi:10.1159/ 000332022

20. Winkler AS, Schaffert M, Schmutzhard E. Epilepsy in a rural African hospital: suggestion for an adjusted classification. Zeitschrift Fur Epileptol. 2008;21:199-208. doi:10.1007/s10309008-0004-y

21. Ezeala-Adikaibe BA, Orjioke C, Ekenze O, et al. Prevalence of active convulsive epilepsy in an urban slum in Enugu South East Nigeria. Seizure. 2016;35:100-105. doi:10.1016/j. seizure.2015.12.010 
22. Stefan H, May TW, Pfäfflin M, et al. Epilepsy in the elderly: comparing clinical characteristics with younger patients. Acta Neurol Scand. 2014;129:283-293. doi:10.1111/ane.12218

23. Johnston A, Smith PEM. Epilepsy in the elderly. Expert Rev Neurother. 2010;10:1899-1910. doi:10.1586/ern.10.170
24. Liberati A, Altman D, Tetzlaff J, et al. The PRISMA statement for reporting systematic reviews and meta-analyses of studies that evaluate health care interventions: explanation and elaboration. Journal of Clinical Epidemiology. 2009;62(10)e1-e34.

\section{Publish your work in this journal}

Neuropsychiatric Disease and Treatment is an international, peerreviewed journal of clinical therapeutics and pharmacology focusing on concise rapid reporting of clinical or pre-clinical studies on a range of neuropsychiatric and neurological disorders. This journal is indexed on PubMed Central, the 'PsycINFO' database and CAS, and is the official journal of The International Neuropsychiatric Association (INA). The manuscript management system is completely online and includes a very quick and fair peer-review system, which is all easy to use. Visit http://www.dovepress.com/testimonials.php to read real quotes from published authors.

Submit your manuscript here: https://www.dovepress.com/neuropsychiatric-disease-and-treatment-journal 